www.jmscr.igmpublication.org

Impact Factor (SJIF): 6.379

Index Copernicus Value: 71.58

ISSN (e)-2347-176x ISSN (p) 2455-0450

crossref DOI: https://dx.doi.org/10.18535/jmscr/v6i6.33

Journal Of Medical Science And Clinical Research

\title{
Correlation of levels of Prostate Specific Antigen with Histopathological findings in patient diagnosed with prostate adenocarcinoma: A study from Central India
}

\author{
Authors \\ Dr Anshu Hotani, Dr Neha Ramsinghani* \\ *Corresponding author \\ Dr Neha Ramsinghani \\ Senior Resident, Netaji Subash Medical College, Jabalpur, MP India
}

\begin{abstract}
Introduction: Prostate cancer is the second most common malignant tumor in western males and anatomically involves the prostate peripheral zone. It is the most common type of cancer in men. To prevent an equal rise in mortality, early detection of prostate cancer will become essential, as will the detection of premalignant lesions such as prostatic intraepithelial neoplasia. Prostate cancer can only be diagnosed by thorough histopathological examination of prostatic tissue along with serum PSA levels estimation.

Material and Methods: A Cross sectional study done over a period of 18months, was carried out on 150 prostate specimens. The specimens were examined for various prostatic pathologies by doing histopathological examination \& their serum total PSA values were correlated. Patients diagnosed as prostate adenocarcinoma were included. On the contrary inadequate biopsy material cases, autolyzed specimen and patients younger than 40 years were not included.

Results: Amongst 38 (25.3\%) adenocarcinoma cases, 15 cases (10.0\%) were well differentiated, 08 cases (5.3\%) were intermediate grade, 03 cases $(2.0 \%)$ were moderately to poorly differentiated and 12 cases $(8.0 \%)$ were poorly differentiated.

Discussion: The percentage of occurrence of occult carcinoma has significantly decreased over the years due to advanced investigative procedures like TRUS, serum PSA level estimation etc.

Conclusion: A combination of staging, grading and follow- up study is required to obtain best predictive values.

Keywords: PSA, Prostate cancer, Adenocarcinoma prostate.
\end{abstract}

\section{Introduction}

Carcinoma prostate is of significant importance to public health, affecting millions of older men globally. Current disease trends in the US, Europe and other regions suggest that the incidence and prevalence of these conditions will increase in the near future due to aging of the world population and the increased prevalence of the metabolic syndrome and its components, thereby placing even greater burdens on finite resources. Prostate cancer is an important growing health problem, presenting a challenge to urologists, radiologists and pathologists. Currently many men are identified as having early prostate cancer through 
the use of serum prostate specific antigen (PSA) screening. Prostate was believed to be a lobular structure for many years. Prior to 1906, when Home described the middle lobe, prostate was considered to be composed of only 2 lateral lobes. Later the existence of 5 prostatic lobes was proposed- 2 lateral lobes, an anterior lobe, posterior lobe \& middle lobe based on its embryonic findings. The prostate gland is topic of discussion now a days due to its late postnatal adult growth changes, enlarged due to benign nodular hyperplasia, and the male health effects of prostate cancer. Prostate cancer is the second most common malignant tumor in western males and anatomically involves the prostate peripheral zone [1]

Berry et al reported the prevalence of BPH is about $8 \%$ during the fourth decade, but it reaches $50 \%$ in the fifth decade and $75 \%$ in the eighth decade. Now a days it is become easier to diagnose prostatic disease by many ways which include DRE (Digital rectal examination of prostate), estimation of serum PSA levels, Prostatic biopsy \& histopathological examination of prostate specimen. ${ }^{[2]}$ The prevalence of $\mathrm{BPH}$ rises markedly with age. Autopsy studies have observed a histological prevalence of $8 \%, 50 \%$ and $80 \%$ in the 4th, 6th and 9th decades of life, respectively $^{[3]}$.

Multiple observational studies from Europe, the US and Asia have demonstrated older age to be a risk factor for BPH onset and clinical progression by several different metrics ${ }^{[4]}$. Prostate volume also increases with age, with data from the Krimpen and Baltimore Longitudinal Study of Aging (BLSA) cohorts suggesting a prostate growth rate of $2.0 \%$ to $2.5 \%$ per year in older men $[5,6]$. Current estimates are that the number of individuals 80 years and older in the US will rise from 9.3 million in 2000 to 19.5 million in 2030, an increase of over $100 \%^{[7]}$.

With the exclusion of non-melanomatous skin malignancy, prostate cancer is the second most prevalent cancer in men globally. The International Agency for Research on Cancer reported that Carcinoma prostate accounted for $14 \%$ of cancers diagnosed in men and over 900, 000 cases were diagnosed throughout the world in 2008 alone. It is the most common type of cancer in men in the United States, with 186,000 new cases in 2008 and 28,600 deaths ${ }^{[8]}$.

To prevent an equal rise in mortality, early detection of prostate cancer will become essential, as will the detection of premalignant lesions such as prostatic intraepithelial neoplasia. Prostatic intraepithelial neoplasia is now considered to be the most important precursor of prostate cancer and can only be diagnosed by thorough histopathological examination of prostatic tissue along with serum PSA levels estimation. ${ }^{[9][10]}$

\section{Material and Methods}

Study Design: Cross sectional study conducted in Department of pathology, Ruxmaniben Deepchand Gardi Medical College Ujjain done over a period of one and a half years. The patients undergoing surgical procedures including prostate biopsy, transurethral resection prostate, prostatectomy with above complaints.

The present study was carried out on 150 prostate specimens. The specimens were examined for various prostatic pathologies by doing histopathological examination \& their serum total PSA values were correlated. Patients diagnosed as prostate adenocarcinoma were included. On the contrary inadequate biopsy material cases, autolyzed specimen and patients younger than 40 years were not included.

\section{Histological pathological Examination [11] [12] Grossing}

After proper labelling \& entry of patient's details in the record register grossing was done. The specimens were received formalin fixed in our histology section from surgery department. If TURP chips are received then take the proper measurment of the specimen in CC. In cases of prostatectomy specimen correct sectioning of tissue is mandatory and the sections are taken from the representative areas. 
Tissue processing: Tissue processing is done under following steps.

Fixation- It is commonly done by formalin. The formalin is commercially available as saturated solution of formaldehyde gas in water. For fixation of tissue, a $10 \%$ solution is used which is prepared by dissolving $10 \mathrm{ml}$ of commercially available formalin in $90 \mathrm{ml}$ of water. It takes 6-8 hours for fixation at room tempreture. The amount of fixative required is $15-20$ times the volume of the specimen.

Dehydration- This is a process in which water from the cells \& tissue is removed so that this space is subsequently taken up by wax. It is carried out by passing the tissue through a series of ascending grades of alcohol: $70 \%, 80 \%, 95 \%$ \& absolute alcohol.

Clearing- This is the process in which alcohol from tissue $\&$ cells is removed $\&$ is replaced by a fluid in which wax is soluble $\&$ it also makes the tissue transparent. Xylene is used for this purpose.

Impregnation- This is the process in which empty spaces in the tissue \& cells after removal of water are taken up by paraffin wax. This hardens the tissue which helps in tissue cutting. Impregnation is done in molten paraffin wax which has the melting point of $56^{0} \mathrm{C}\left(54-56^{0 \mathrm{C}}\right)$.

Now a days all above processes of fixation, dehydration, clearing \& impregnation are carried out in a special equipment which is known as automatic tissue processor (histokinet). The tissue processor has 12-16 glass jars for formalin, ascending grades of alcohol, xylene \& thermostatically controlled two paraffin wax baths to keep paraffin wax in molten state. Tissue moves automatically by hydraulic mechanism from one jar to another after fixed time schedule and the whole process 16-22 hours.

\section{Embedding \& Blocking}

Embedding of tissue is done in molten wax. Wax blocks are conventionally prepared using metallic moulds placed over a smooth surfaced glass tile. Molten wax poured in the cavity in moulds. The processed tissue pieces are put in to wax with number tags \& examining surface facing downwards. Wax is allowed to solidify, after solidification L-moulds are removed while plastic moulds remains with the wax block.

\section{Microtomy}

In this procedure the blocks are kept in a microtome for cutting of sections. Most commonly rotary microtome is used. In this the knife is fixed while the tissue block is movable.

In this the stainless steel knife faces upwards $\&$ is wedge shaped. Put the paraffin block having tissue in it in rotary microtome.

Cut the section by operating the microtome manually after adjusting the thickness at 5-6 $\square \mathrm{m}$. Sections are picked from the knife with the help of a forceps.

These are made to float in a water bath which is kept at temperature of $40-45^{\circ} \mathrm{C}$ i.e slightly below the melting point of wax. This removes folds in section.

From water bath sections are picked on a clean glass slide coated with egg albumin. The glass slide is placed in an oven maintained at a temperature of $56^{\circ} \mathrm{C}$ for $20-30$ minutes for proper drying $\&$ better adhesion.

Hematoxylin and Eosin staining procedure ${ }^{[13]}$

Nuclei-blue, Cytoplasm-pink. All the lesions were graded into non-neoplastic \& neoplastic lesions. The cases of prostatic adenocarcinoma were graded using Gleason microscopic grading.

PSA Measurement: Serum total PSA values were measured on VITROS-ECI machine. The specimens recommended are serum, heparin plasma, EDTA plasma. While the specimens not recommended are turbid specimens as turbidity affects test results.

\section{Specimen Collection and Preparation}

- Thoroughly mix samples by inversion and bring to $15-30{ }^{\circ} \mathrm{C}\left(59-86^{\circ} \mathrm{F}\right)$ before use.

- The VITROS PSA test uses $15 \mu \mathrm{L}$ of sample for each determination.

- The blood sample for prostate-specific antigen (PSA) testing should be 
centrifuged, and the serum should be separated within 2-3 hours.

- If the assay is not performed within the next 2-3 hours, the serum should be frozen. Reliability of the protein is believed to be maintained when the specimen is frozen at less than $-20^{\circ} \mathrm{C}$ for several weeks

\section{Handling and Storage Conditions}

- Handle samples in stoppered containers to avoid contamination and evaporation.
- The amount of time samples are on the system prior to analysis should be limited to avoid evaporation.

- Return to $2-8{ }^{\circ} \mathrm{C}\left(36-46{ }^{\circ} \mathrm{F}\right)$ as soon as possible after use, or load sufficient volume for a single determination.

- Serum and plasma samples may be stored for up to 7 days at $2-8{ }^{\circ} \mathrm{C}\left(36-46^{\circ} \mathrm{F}\right)$ or 4 weeks at $-20{ }^{\circ} \mathrm{C}\left(-4{ }^{\circ} \mathrm{F}\right)$.

- Avoid repeated freeze-thaw cycles.

Table 1 Details of Vitros- ECI

\begin{tabular}{|c|c|c|c|c|c|}
\hline Test Type & System & $\begin{array}{c}\text { Incubation } \\
\text { Time }\end{array}$ & $\begin{array}{c}\text { Time to first } \\
\text { Result }\end{array}$ & $\begin{array}{c}\text { Test } \\
\text { Temperature }\end{array}$ & $\begin{array}{c}\text { Reaction } \\
\text { Sample Volume }\end{array}$ \\
\hline Immunometric & Vitros ECi/ECiQ, & 29 minutes & 37 minutes & $37^{\circ} \mathrm{C}$ & $15 \mu \mathrm{L}$ \\
\hline
\end{tabular}

\section{Procedure}

- Reagent tray: The micro wells are kept on reagent tray with the readymade reagent. Each reagent tray has capacity to accommodate 25 wells.

Sample Assembly: The sample assembly part of ECI machine has magnetic field on which the sampling tray is kept \& which revolves on its own axis. The sample is kept on the sampling tray from here the sample is automatically sucked by the tips attached to provosis inside the machine.

- Now, wells are pushed into the incubator by the probe followed by release of sample into the same well. The temperature of incubator has to be maintained between $36-38^{0} \mathrm{C}$.

- After processing of sample in incubator, the wells shuttles to the inner ring of the incubator, then the luminometer reads the values of PSA \& displays it on the monitor of machine.

\section{Statistical analysis}

Results were presented as Mean $+_{-}$SD and range for quantitative data and number $\&$ percentage for qualitative data. Group wise comparisons were made using Unpaired T- test. P value of 0.005 or less was considered for statistical significance.

\section{Results}

Table 2 Distribution of patients according to Gleason Grade ( $\mathrm{N}=150)$

\begin{tabular}{|l|c|c|}
\hline Gleason Grading & Number & Percentage \\
\hline Grade-1 & 15 & $10.00 \%$ \\
\hline Grade-2 & 8 & $5.33 \%$ \\
\hline Grade-3 & 3 & $2.00 \%$ \\
\hline Grade-4 & 12 & $8.00 \%$ \\
\hline None & 112 & $74.67 \%$ \\
\hline Total & 150 & $100.00 \%$ \\
\hline
\end{tabular}
adenocarcinoma group and they were scored from 2-10. According to the scores, adenocarcinoma was graded as well differentiated (score 2-4), intermediate grade (score 5-6), moderately to poorly differentiated (score 7) \& poorly differentiated (score 8-10).

Amongst 38 (25.3\%) adenocarcinoma cases, 15 cases $(10.0 \%)$ were well differentiated, 08 cases $(5.3 \%)$ were intermediate grade, 03 cases $(2.0 \%)$ were moderately to poorly differentiated and 12 cases $(8.0 \%)$ were poorly differentiated.

\section{Discussion}

There is close association of increased serum total PSA levels and prostatic disease like BPH, PIN, $\mathrm{Ca}$ prostate, prostatitis etc. Increased PSA levels can indicate the disease even before any invasive procedure like prostatic biopsy. In view of high 
degree of association of HGPIN with prostatic carcinoma, it is suggested that these HGPIN patients need close follow-up, observations and investigations to rule out existence of carcinoma, especially in the peripheral zone. ${ }^{[15][16][21]}$

$38(25.3 \%)$ cases showed microscopic features of adenocarcinoma. It is comparable with the various studies done; Haroun et al showed 27.1\%, Jasani et al showed 32\%, while Djavan et al and Jevan et al showed $17 \%$ cases with adenocarcinoma. In present study out of 38 cases of adenocarcinoma, 30 cases $(78.9 \%)$ were above 65 years of age. It is comparable with study done by Shimada et al \& Xie et al who found $75 \%$ \& $84.2 \%$ cases with adenocarcinoma respectively, were above 65 years of age. Jasani et al also showed $84.4 \%$ cases of adenocarcinoma of prostate between age group of 61-70 years. In the present study, mean age of patients with adenocarcinoma was $70.6 \pm$ 10.4 years which is comparable with the studies done; Thompson et al showed mean age of 69 years, David C. Miller et al showed mean age of 68 years, Jasani et al showed mean age $65.82 \pm$ 5.61 years \& Lyn et al showed mean age of 65 years for Ca prostate. ${ }^{[15-24]}$

In the present study, 38/150 cases (25.3\%) showing prostatic adenocarcinoma, Gleason score of 2-4 (well differentiated), 5-6 (moderately differentiated), 7 (moderately to poorly differentiated), 8-10 (poorly differentiated) were noted in $39.4 \%, 21.0 \%, 8.0 \%$ and $31.6 \%$ cases respectively. The various studies done by Mwakyoma and Mabandi showed 5.3\%, 61.1\% and $33.6 \%$ cases had Gleason score of 2-4, 5-7 and 8-10 respectively; Divrik et al observed 9.7\%, $76.7 \%$ and $13.6 \%$ cases having Gleason score of 2-4, 5-7 and 8-10 respectively. ${ }^{[16-25]}$

The results for the cases with Gleason scoring between 8-10 i.e poorly differentiated tumours are comparable to other studies. Thus, the present study shows more number of cases with gleason's score 2-4. This may be because of regular screening, follow up \& early treatment of patients coming with symptoms of prostatic pathology in our institute. Thus, low grade malignancies are treated well in time \& are not allowed to progress to higher grades. ${ }^{[13][23][24]}$

We found that the distribution of adenocarcinoma prostate cases in relation to PSA values as $0 \%$, $0 \%, 13.16 \% \& 86.64 \%$ with PSA values $0-4,4-$ $10,10-40,>40 \mathrm{ng} / \mathrm{ml}$ respectively. So in present study there are $86.64 \%$ of cases with PSA values $>10 \mathrm{ng} / \mathrm{ml}$. Similar results were obtained in study done by Jasani et al who showed $86.2 \%$ cases having serum total PSA values > $10 \mathrm{ng} / \mathrm{ml}, H . A$ Mwalyoma et al showed $94.7 \%$ cases with PSA values $>10 \mathrm{ng} / \mathrm{ml}$, Sladana Zivkovic et al showed $70.0 \%$ in cases with PSA values 10-40 ng/ml. Whereas Kshitij et al showed $63.15 \%$ cases in PSA range $>10 \mathrm{ng} / \mathrm{ml}^{[27-30]}$ Therefore, In view of increasing trend of the occurrence of both neoplastic and non-neoplastic lesions of the prostate in the elderly, the current study aims at evaluating the histomorphological features of prostate specimens with its correlation to serum PSA levels. Evaluation of serum total PSA levels in patients having complaints of prostatism helps in estimating the extent of disease, this also incidates the level of prostate involvement \& extraprostatic extension even before other invasive procedure like biopsy is done. Prostate specific antigen (PSA) is a kallikrein like serine protease produced exclusively by the epithelial cells of the prostate. Although increased PSA levels have been found to be closely associated with prostate cancer, there can be different reasons for an elevated PSA level, including benign prostatic hyperplasia, prostatitis, prostatic trauma, and prostatic infarction. ${ }^{[25-30]}$

\section{Conclusion}

Conventional adenocarcinoma forms the most common type of prostatic carcinoma and well differentiated patterns were frequently recognized. The percentage of occurrence of occult carcinoma has significantly decreased over the years due to advanced investigative procedures like TRUS, serum PSA level estimation etc. A combination of staging, grading and follow- up study is required to obtain best predictive values. 


\section{References}

1. Siegel R, Naishadham D, Jemal A. Cancer statistics, 2013. CA: A Cancer Journal for Clinicians. 2013;63(1):11-30.

2. Eble JN, Sauter G, Epstein JI, Sesterhenn IA (Eds.). World Health Organization Classification of Tumours. Pathology and Genetics of Tumours of the Urinary System and Male Genital Organs. IARC Press: Lyon 2004. 158, 193-195, 169-172.

3. Barry MJ, Fowler FJ, Jr, Bin L, Pitts JC, 3rd, Harris CJ, Mulley AG., Jr The natural history of patients with benign prostatic hyperplasia as diagnosed by North American urologists. J Urol. 1997;157:104.

4. Bosch JL, Hop WC, Kirkels WJ, Schröder FH. Natural history of benign prostatic hyperplasia: Appropriate case definition and estimation of its prevalence in the community. Urology. 1995;46:34-40

5. Bosch JL, Tilling K, Bohnen AM, Bangma $\mathrm{CH}$, Donovan JL. Establishing normal reference ranges for prostate volume change with age in the population-based Krimpen-study: Prediction of future prostate volume in individual men. Prostate. 2007;67:1816-24.

6. Loeb S, Kettermann A, Carter HB, Ferrucci L, Metter EJ, Walsh PC. Prostate volume changes over time: Results from the Baltimore Longitudinal Study of Aging. J Urol. 2009;182:1458-62.

7. Centers for Disease Control and Prevention (CDC). Trends in aging-United States and worldwide. MMWR Morb Mortal Wkly Rep. 2003;52(6):101-4. 106.

8. Jemal A, Siegel R, Ward E, Hao Y, Xu J, Murray T, Thun MJ (March 2008). "Cancer Statistics,2008". CA Cancer J Clin 58 (2): 71-96.doi:10.3322/ CA.2007. 0010. PMID 18287387.

9. Liwei Huang, Yongbing Pu, Wen Yang Hu, Lynn Birch, Douglas Luccio-Camelo, Terry Yamaguchi, Gail S Prins The role of
Wnt5a in prostate gland development.Dev.

Biol.: 2009, 328(2);188-99 PMID: 19389372

8 Jump up Chad M Vezina, Tien-Min Lin, Richard E Peterson AHR signaling in prostate growth, morphogenesis, and disease. Biochem. Pharmacol.: 2009, 77(4);566-76PMID: 18977204.

9 Junn D. Chavez, Jr. Basic Immunohistochemistry HTL (ASCP) QIHC Quality Control Laboratory, Lab Vision Corporation 2009

10 Bancrofft John D. Theory and practice of histological techniques 5 th edition.

11 Jasani JH, Patel HB, Gheewala B, Vaishnani HV, Bhuva K, Sancheti S, Patel A, Tandon R. IJBAR. 2012; 03: 268-272.

12 Haroun AA, Hadidy AS, Awwad ZM, Nimri CF, Mahafza WS, Tarawneh ES. Utility of free prostate specific antigen serum level and its related parameters in the diagnosis of prostate cancer. Saudi J Kidney Dis Transpl. 2011 Mar; 22(2):2917.

13 Pacelli A, Bostwick DG. Clinical significance of high grade prostatic intra epithelial neoplasia in transurethral resection specimens. Urology.1997; 50:355- 359 .

14 Nishant D. Patel et al. Epidemiology and etiology of benign prostatic hyperplasia and bladder outlet obstruction. Indian J Urol. 2014 Apr-Jun; 30(2): 170-176.

15 Mwakyoma HA. The Prevalence of High Grade Prostatic Intraepithelial Neoplasia in Prostatic Biopsies Diagnosed As benign Prostatic Hyperplasia at Muhimbili National Hospital, Dar es Salaam. Tanzania Medical Journal. 2008; 23 (1): 1-4.

16 David G Bostwick1 et al. High-grade prostatic intraepithelial neoplasia. Modern Pathology (2004) 17, 360-379, advance online publication, 23 January 2004

17 Skjorten FJ, Berner A, Harvei S, Robsahm TE, Tretli S. Prostatic intraepithelial neoplasia in surgical resections. 
Relationship to coexistent adenocarcinoma and atypical adenomatous hyperplasia of the prostate. Cancer. 1997; 79: 1172-1179

18 Rekhi B, Jaswal TS, Arora B. Premalignant lesions of prostate and their association with nodular hyperplasia and carcinoma prostate. Indian J Cancer. 41: 60-65.

19 Shimada H, Misugi K, Sasaki Y, lizuka A, Nishihira H. Carcinoma of the prostate in childhood and adolescence. Report of a case and review of the literature. Cancer. 1980; 46: $2534-42$.

20 Xie LP, Qin J, Zheng XY, Shen HF, Chen ZD, Cai SL, Zhang ZG, Ding W, Ren GP, Wang LJ, Yu XR. Age and pathological features of 481 prostate cancer patients. Zhonghua Nan Ke Xue. 2005 Jun; 11(6):428-30.

21 David C. Miller et al. Prostate Carcinoma Presentation, Diagnosis, and Staging. An Update from the National Cancer Data Base. 2003 American Cancer Society DOI10.1002/cncr.11635 June 23, 2003.

22 Lyn NNK, Collins GN, Alex AK, Brown SCW, Brooman PJ, O'reilly PH. Prostate specific antigen parameters in clinical practice. The prostate Journal. 2(4): 205210.

23 Mwakyoma HA, Mabandi JL. Correlation of Gleason's score and pretreatment prostate specific antigen in patients. Professional Med J Jun 2010; 17(2): 235240.

24 Divrik RT, Erog A, Sahin A, Zorlu F, Ozen $H$. Increasing the number of biopsies increases the concordance of Gleason's score's of needle biopsies and prostatectomy specimens. Urol Oncol semin. 2007; 25: 376-82.

25 Kshitij A. jyoti sapre, A.S.Agnihotri et al: Utility of prostate specific antigen in different prostatic lesion: Pathology and laboratory medicine; Jun 2011; Vol 3 issue $1: 18-23$.
26 Brawer MK, Lange PH, Prostate-specific antigen and premalignant change: implications for early detection. CA 1989; 39: 361-75.

$27 \mathrm{H}$ A Mwaakyoma et al. Correlation of Gleason"s score and pretreatment prostate specific antigen in patients. Professssional Med J Jun 2010; 17(2) : 235-240.

28 Sladana Zivkovic et al: Correlation prostate specific antigen and histopathologicl difference of prostate carcinoma; arch Oncol 2004;12(3) 148-51. 